\title{
ATENÇÃO FARMACÊUTICA EM DERMATOLOGIA: FÁRMACOS E
} ANTIACNEICOS

\author{
Mariana Piana*; Gisele Scotti do Canto** \\ Universidade Federal de Santa Maria
}

\begin{abstract}
RESUMO: Atenção farmacêutica é um modelo de prática farmacêutica que compreende atitudes, valores éticos, conhecimento científico, habilidades de comunicação e responsabilidades por parte do farmacêutico sobre a farmacoterapia, o uso racional de medicamentos e a prevenção de doenças. Para uma atenção farmacêutica adequada, o Farmacêutico dispõe de técnicas para realizar a dispensação dos medicamentos visando 0 entendimento do tratamento pelo paciente. Entre os principais medicamentos prescritos para o tratamento da acne, doença inflamatória crônica do folículo pilosebáceo, estão os antibióticos e os retinóides, cuja potência farmacológica está associada a importantes efeitos toxicológicos. Neste sentido, a orientação ao paciente no momento da dispensação, quanto ao uso correto do medicamento, contra-indicações, possíveis reações adversas e interações medicamentosas, serão extremamente importantes para garantir uma terapia segura e eficaz.
\end{abstract}

Descritores: Acne; Antiacneicos; Atenção farmacêutica; Fichas posológicas

\section{PHARMACEUTICAL CARE IN DERMATOLOGY: ANTIACNEICS DRUGS}

ABSTRACT: Pharmaceutical care is a model of pharmaceutical practice which includes attitudes, ethical values, scientific knowledge, communicative skills and responsibilities of the pharmaceutical professional about the pharmacotherapy, the rational use of medicine and disease prevention. In order to have an adequate pharmaceutical care, the pharmaceutical professional has techniques to carry out the drug distribution aiming the understanding of treatment by the patient. Among the main acne prescribed drugs, chronic inflammatory disease of the pilosebaceous follicle, are the antibiotics and the retinoids, whose pharmacological power is associated to the important toxicological effects. Thus, the patient orientation at the drug distribution, as to the correct use of the drug, contraindications, possible adverse reactions and drug interactions, are going to be extremely important in order to guarantee a safe and efficient therapy.

Descriptors: Acne; Antiacneics; Pharmaceutical care; Chips dosing

\footnotetext{
* Aluna do Curso de Pós-graduação em Ciências Farmacêuticas, Universidade Federal de Santa Maria, Rio Grande do Sul, Brasil.

** Professora Doutora do Programa de Pós-Graduação em Ciências Farmacêuticas, Universidade Federal de Santa Maria, Rio Grande do Sul, Brasil.
} 


\section{Introdução}

A "Atenção Farmacêutica" é um modelo de prática farmacêutica desenvolvida no contexto da assistência farmacêutica. Compreende atitudes, valores éticos e compromissos na prevenção de doenças, promoção e recuperação da saúde de forma integrada à equipe de saúde. É a interação direta do farmacêutico com o paciente, visando uma farmacoterapia racional e a obtenção de resultados definidos e mensuráveis voltados para a melhoria da qualidade de vida. ${ }^{1}$

A farmacoterapia adequada e a condição clínica e psicológica do paciente são elementos essenciais para o desenvolvimento dessa prática farmacêutica, uma vez que, a utilização dos medicamentos é influenciada por fatores de natureza cultural, social, econômica e política. ${ }^{1,2}$

No Brasil, desde 1996, os medicamentos ocupam a primeira posição entre os três

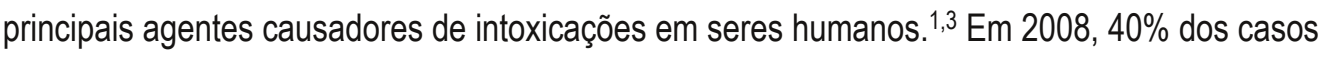
de intoxicação, no estado de São Paulo, foram causados por medicamentos e $50 \%$ das reinternações no estado do Rio de Janeiro, tiveram origem na utilização incorreta dos medicamentos prescritos ou no abandono do tratamento. ${ }^{4}$

Pesquisas realizadas em diferentes países da América do Norte e da Europa mostram um impacto favorável da atenção farmacêutica sobre a efetividade, qualidade de vida e custos assistenciais, ${ }^{1,3}$ demonstrando ser um ótimo modelo para a economia, principalmente para países em desenvolvimento que possuem um sistema de saúde com escassos recursos financeiros.

O farmacêutico deve possuir, além da formação científica, habilidade de comunicação com a equipe de trabalho e com os pacientes. $O$ não seguimento das prescrições, em muitos casos, reflete a falta de posição educativa fundamentada na relação farmacêutico/paciente. ${ }^{5}$ Deste modo, é muito importante conhecer o grau de instrução dos pacientes, a fim de direcionar melhor as técnicas de comunicação, tanto oral como escrita no momento da orientação. ${ }^{6}$

$\mathrm{Na}$ área dermatológica, especialmente em relação a acne, a atuação do farmacêutico deve conter esses dois fatores, uma vez que, a longo prazo, poderá haver desenvolvimento de alterações psicológicas, ${ }^{7,8}$ devido ao aparecimento de lesões ou cicatrizes antiestéticas, levando o paciente a apresentar considerável desconforto social, ,8,9,10,11 bem como a ansiedade e a depressão provocadas pelo quadro acneico, características que podem comprometer 0 tratamento e provocar mudanças sociais na vida do paciente. ${ }^{8,9,11}$ Deste modo, a percepção da gravidade da doença é muito importante para a orientação do tratamento. ${ }^{9,10}$

A acne é uma condição inflamatória crônica do folículo pilosebáceo que afeta principalmente o rosto e o tronco superior. ${ }^{11,12,13} 0$ mecanismo de formação da acne envolve uma hiperqueratinização folicular, e com ela, forma-se um tampão córneo que retém 0 conteúdo sebáceo no interior da glândula, sendo este, conhecido como comedão ou cravo. 0 folículo ocluído facilita a ação da Propionibacterium acnes ( $P$. acnes) e leveduras como Pityrosporum orbiculare (P. orbiculare) que liberam proteases hidrolíticas que rompem o lúmem celular expulsando o conteúdo sebáceo para a derme. Os lipídeos sebáceos, pêlos, P. acnes e

Saúde (Santa Maria), v.36, n.2, p. 39-54, jul./dez. 2010. Atenção farmacêutica em dermatologia: fármacos antiacneicos ISSN 2236-5834 epiteliócitos cornificados geram uma resposta imune do tipo corpo estranho. 3,8, 10,11,14,15

É classificada como não inflamatória e inflamatória, e subdividida em graus. Acne nãoinflamatória: comedônica (grau I), acne inflamatória: papulopustulosa (grau II), nodulocística (grau III), conglobata (grau IV), fulminante (grau V). ${ }^{16}$ 
A acne vulgar ou juvenil (grau I) é uma das dermatoses mais frequentes, ${ }^{16}$ causada pelo aumento da produção de sebo pelas glândulas sebáceas após a puberdade. ${ }^{11,15,17}$ Seu tratamento justifica-se pela possibilidade de evitar tanto lesões cutâneas permanentes quanto o aparecimento ou agravamento de transtornos psicológicos, oriundos do abalo à auto-estima ocasionado pelas lesões, que frequentemente acometem face e tronco. ${ }^{16} \mathrm{Na}$ acne papulopustulosa associam-se aos comedões, pápulas e pústulas de conteúdo purulento. ${ }^{9} \mathrm{~A}$ Acne nodulocística caracteriza-se pelo conteúdo sebáceo volumoso e localizado mais profundamente na pele, o que produz endurecimento no local da lesão, ${ }^{15}$ sendo, neste caso, de difícil remoção. ${ }^{11,15,18} \mathrm{Na}$ acne conglobata há formação de abcessos e fístulas. ${ }^{9} \mathrm{~A}$ Acne fulminans é rara, porém severa, devido a uma reação imunológica complexa, causando lesões eruptivas e ulcerosas que deixam cicatrizes, principalmente na parte superior torácica. ${ }^{11,15,18}$ Predominam sintomas sistêmicos de início súbito como febre, perda de peso, astenia, adenopatia, comprometimento osteoarticular e presença de osteólise. ${ }^{15}$

A acne desenvolve-se por volta dos 12 anos em homens e mulheres, sendo mais precoce no sexo feminino, podendo permanecer até os 25 anos de idade. ${ }^{12,13}$ Estima-se que esta doença atinja milhões de pessoas mundialmente, 10 com prevalência de $94,4 \%$ em homens e $92 \%$ em mulheres, ${ }^{11}$ provocando, muitas vezes, alterações físicas e psicológicas. Nas mulheres, principalmente, o nível de estresse e a gravidade das lesões ocasionadas pela acne podem estar correlacionados com a severidade e a sua persistência durante o tratamento. ${ }^{12,13}$

A conexão entre farmacêutico e o paciente em considerável alteração psicológica, é de fundamental importância na atenção farmacêutica, uma vez que o farmacêutico é um dos responsáveis pela orientação da farmacoterapia racional e pelo alcance do objetivo terapêutico previsto.

Neste sentido, a atenção farmacêutica, um modelo centrado no paciente, surge, portanto, como alternativa em busca de melhorar a qualidade do processo de utilização dos medicamentos para 0 alcance de resultados concretos e satisfatórios. ${ }^{1}$

O objetivo deste estudo é, portanto, promover subsídios aos profissionais farmacêuticos para a realização da atenção farmacêutica na área dermatológica, especificamente quanto ao uso de fármacos antiacneicos.

\section{Metodologia}

Esta pesquisa foi realizada através da análise artigos científicos disponíveis principalmente nas bases de dados do Scopus e ScienceDirect, sendo os descritores utilizados: acne, fármacos antiacneicos e atenção farmacêutica.

A organização das informações foi realizada na forma de tabela para auxiliar a orientação farmacêutica. Para o paciente, as informações foram organizadas na forma de "Mini bulas", contendo apenas as informações clínicas mais relevantes, como o modo de usar, as principais contra-indicações, as interações com medicamentos e/ou alimentos e as reações adversas mais frequentes que possam ocorrer durante o uso do medicamento, proporcionando, assim, um maior controle sobre o seu tratamento e a possibilidade de informar o médico do surgimento destas reações. Foram, também, elaboradas fichas posológicas de orientação ao paciente, as quais auxiliariam, principalmente, pacientes com diferentes níveis de alfabetização, quanto ao horário correto do uso do medicamento (vide dados suplementares).

Saúde (Santa Maria), v.36, n.2, p. 39-54, jul./dez. 2010 Piana,M.; Canto, G. S. ISSN 2236-5843 


\section{Resultados}

O tratamento da acne é realizado principalmente através do emprego de antimicrobianos, retinóides e agentes abrasivos.

Os antimicrobianos são compostos que em baixa concentração inibem ou reduzem 0 crescimento de diversos microorganismos. ${ }^{12}$ Entre estes, os mais empregados no tratamento da acne estão o ácido azeláico e o peróxido de benzoíla.

Em preparações tópicas, 0 ácido azeláico possui efeito hipopigmentante, ${ }^{7,19}$ podendo causar, como efeito adverso irritação local e fotossensibilização., ${ }^{7,15,19,20}$ Não é considerado como tratamento de primeira escolha, mas é uma boa alternativa para acne leve a moderada ou com hiperpigmentação pós-inflamatória. ${ }^{15,20}$ É relativamente atóxico, e não há evidência de interação medicamentosa com outros fármacos devido a sua baixa absorção sistêmica. ${ }^{19}$ Quanto ao modo de usar, indicam-se duas aplicações diárias na pele afetada na forma de creme ou gel entre $5 \%$ a $15 \%,{ }^{7}$ durante seis meses. ${ }^{7,19}$ Sua utilização com peróxido de benzoíla, clindamicina, tretinoína ou eritromicina aumentam sua eficácia. ${ }^{20}$

O peróxido de benzoíla possui atividade secante e descamativa, ${ }^{19,21}$ o que ajuda na sua eficácia, não devendo ser aplicado sobre a pele irritada ou em queimaduras pelo vento ou sol. ${ }^{12}$ É contra indicado em pessoas hipersensíveis a esta substância. ${ }^{20}$ Os efeitos adversos mais freqüentes são ressecamento, enrijecimento da pele e sensação de ardor. ${ }^{21}$ Não é aconselhado aplicar juntamente com preparações tópicas como retinóides e antibióticos devido ao efeito irritante. 2,12,20,21 Comercialmente, está disponível na forma de gel e creme em concentrações de $1 \%$ a $10 \%$, podendo ser usado na pele afetada de uma a duas vezes ao dia. ${ }^{12,19,20}$

Entre os agentes antimicrobianos estão, também, os antibióticos, empregados nas infecções bacterianas. Os antibióticos são normalmente prescritos nos casos de acne moderada a grave. ${ }^{17}$ Entre estes, estão a tetraciclina, empregada via sistêmica, a eritromicina tanto por via tópica como sistêmica e a clindamicina somente por via tópica. Estes fármacos apresentam, em comum, como principal efeito adverso, transtornos gastrointestinais, bem como indução à resistência, devendo-se, portanto, ser rigorosamente respeitado o horário da sua utilização. ${ }^{23}$

A tetraciclina foi, por muito tempo, o medicamento de eleição para a terapia da acne, devido sua eficácia, tolerância e margem de segurança elevada. No entanto, deixou de ter prevalência, devido os seus efeitos adversos e interações com outros medicamentos. ${ }^{15,23}$ Os efeitos adversos atribuídos ao uso da tetraciclina são transtornos renais,19 fotossensibilidade, ${ }^{11,19,21,23}$ aumento dos níveis das enzimas hepáticas produzindo hepatotoxidade, pancreatites, toxicidade do sistema nervoso central, colites pseudomembranosas, reações de hipersensibilidade e vaginite por Candida. ${ }^{19,21,23}$ Antiácidos, leite e alimentos que contenham cálcio, magnésio e ferro, também, não devem ser utilizados durante $o$ tratamento, pois formam complexos com a tetraciclina, diminuindo a sua absorção. A associação com retinóides pode causar hipertensão intracraniana. ${ }^{18,19,20,24}$ Caulim, pectina e colestipol diminuem a absorção da tetraciclina, pois são adsorvidos nesta. ${ }^{25}$ Os efeitos nefrotóxicos potencializam juntamente com metoxiflurano e outros diuréticos que possuam como efeito adverso a nefrotoxicidade. ${ }^{19}$ Geralmente, indicam-se doses de $500 \mathrm{mg}$ de tetraciclina, duas vezes ao dia. ${ }^{12,20,26} \mathrm{~A}$ tetraciclina é contra indicada na insuficiência hepática e

Saúde (Santa Maria), v.36, n.2, p. 39-54,

jul./dez. 2010.

Atenção farmacêutica em dermatologia: fármacos antiacneicos ISSN 2236-5834 renal, na gravidez e em crianças. 0 uso de tetraciclina entre $02^{\circ}$ trimestre da gravidez até cerca de 8 anos de idade também é contra indicado, devido à fixação do fármaco nos dentes em desenvolvimento, causando trocas de cor e hipoplasia do esmalte. ${ }^{19}$ 
A eritromicina é o antibiótico de menor emprego para o tratamento da acne devido à resistência por $P$. acnes e Stapylococcus epidermidis. ${ }^{15}$ Sua utilização é contra indicada na hipersensibilidade à eritromicina e hepatopatias. ${ }^{15,20,22}$ Também durante a gravidez e amamentação não deve ser utilizada, pois a eritromicina pode atravessar a placenta, bem como distribuir-se no leite materno. Os principais efeitos adversos causados pelo uso da eritromicina são náuseas e colites pseudomembranosas. Outros efeitos como perda da audição e hepatites também podem ocorrer. ${ }^{19,20,22,23}$ Por via tópica evidencia-se, principalmente, descamação, irritação e ressecamento da pele. ${ }^{19,21}$ Quanto a interações medicamentosas, a eritromicina inibe o metabolismo hepático da varfarina, carbamazepina e da ciclosporina que são catalizadas pelas enzimas do citocromo P-450, potencializando, consequentemente, os efeitos destes medicamentos que são, respectivamente, 0 prolongamento do tempo de protrombina e aumento do risco hemorrágico, aumento do efeito anticonvulsivante e hepatotoxidade. A eritromicina eleva, também, a concentração sanguínea da digoxina devido à diminuição da flora bacteriana intestinal, responsável pela absorção adequada deste medicamento. A eritromicina aumenta, também, o dano hepático juntamente com medicamentos hepatotóxicos ${ }^{24,25}$ Para uso tópico, não deve ser empregada juntamente com isotretinoína, clindamicina e outras substâncias irritantes para a pele. ${ }^{20}$ Recomenda-se doses de $500 \mathrm{mg} / \mathrm{dia}$ a $1 \mathrm{~g} / \mathrm{dia} ; 250 \mathrm{mg}$ ou $500 \mathrm{mg}$, duas vezes ao dia, ou a cada 6 horas. ${ }^{12,21,22,23} \mathrm{Na}$ forma de creme, a concentração recomendada é de $1,5 \%$ a $4 \%$ podendo ser usada na pele afetada duas vezes ao dia. ${ }^{21,23}$

A clindamicina é uma substância derivada da lincomicina, que reduz a concentração de ácidos graxos livres da pele, diminuindo assim, o crescimento da $P$. acnes ${ }^{15}$. É contra indicada em pacientes que possuam hipersensibilidade à lincomicina, doenças renais e hepáticas, bem como antecedentes de colites. Como principais efeitos adversos estão irritação local, dermatites de contato, ${ }^{19}$ enrijecimento e descamação da pele. ${ }^{7}$ A associação de clindamicina com antibióticos pode desenvolver colites pseudomembranosas ${ }^{19} \mathrm{e}$, associada ao cetoconazol, pode ter sua ação diminuída. ${ }^{20}$ Comercialmente encontra-se como gel $3 \%$ e solução $10 \mathrm{mg} / \mathrm{ml}$. Deve-se aplicar uma fina camada sobre a pele afetada duas vezes ao dia. ${ }^{15,20,21}$

Os retinóides incluem compostos naturais e sintéticos derivados do retinol que exibem atividade de vitamina $A$. Estes compostos interferem em muitas atividades como a proliferação e a diferenciação celular, atividade imune, inflamação e produção de sebo. Os mais empregados são a isotretinoína, por via sistêmica, o adapaleno, o tazaroteno e a tretinoína por via tópica. Devido ao efeito fotossensibilizante destes fármacos, deve-se evitar a exposição solar durante o tratamento. Em geral, o uso concomitante dos retinóides com tetraciclinas não é recomendado devido à hipertensão intracraniana. ${ }^{15,19,24}$ Também, deve ser evitada a associação com a vitamina $A$, devido a problemas de hipervitaminose $A .24,25$

0 tazaroteno é o mais novo retinóide acetilênico sintético introduzido para o tratamento da acne leve a moderada. ${ }^{7,15}$ É contra indicado em pacientes com pele eczematosa, ${ }^{15}$ e na gravidez, devido ao seu pequeno efeito teratogênico. ${ }^{11,15,19}$ Os efeitos adversos mais frequentes são irritação, descamação, sensação de queimação e ressecamento da pele.,3,23,30 Recomenda-se uma aplicação diária de creme $0,1 \%$ ou gel $0,1 \%$ na pele afetada ao anoitecer. ${ }^{19}$

O adapaleno é um ácido naftóico com atividade retinóica, observa-se uma melhor ação anticomedogênica, melhor ação antinflamatória e menor prevalência dos efeitos adversos em relação aos outros retinóicos. ${ }^{7,11,13}$ É contra indicado durante a gravidez.11,15,19,20 Durante 0 tratamento, evitar a exposição ao sol, ${ }^{11,13}$ vento, ou temperaturas muito frias. ${ }^{15,20}$ Os efeitos

Saúde (Santa Maria), v.36, n.2, p. 39-54, jul./dez. 2010 Piana,M.; Canto, G. S. ISSN 2236-5843 
adversos mais frequentes são eritema, prurido e descamação da pele, ${ }^{7,13,19}$ observados principalmente, nas primeiras quatro semanas. ${ }^{13}$ Os retinóides ou medicamentos tópicos de ação similar não devem ser usados concomitantemente. ${ }^{19}$ Este medicamento encontra-se disponível na forma farmacêutica de gel $0,1 \%$ e solução $0,1 \%$, recomenda-se aplicar uma vez ao dia na pele afetada, preferencialmente à noite. $12,15,19,20$

A tretinoína é um derivado da vitamina A que possui ação queratolítica, sendo empregada na acne leve a moderada contendo pápulas e pústulas. ${ }^{15}$ É contra indicada na gravidez por ser teratogênica, ${ }^{7,11,15,19,20}$ em pacientes com diabetes mellitus, hiperlipidemias, ${ }^{7,15,19,20}$ hipervitaminose $A$ e insuficiência hepática. ${ }^{19}$ Os efeitos adversos mais frequentes são ardor, irritação da pele e eritema severo.7,14,15,19,20 A associação com medicamentos tópicos de alta concentração alcoólica ocorre aumento do ressecamento e da irritação epidérmica. ${ }^{15,21,25}$ É comercializada na forma de creme $0,1 \%$ e gel $0,1 \%$, recomendando-se uma a duas aplicações diárias na pele afetada. ${ }^{15,19,20}$

A isotretinoína é um fármaco revolucionário derivado da vitamina $A$. Age simultaneamente em todos os mecanismos de patogênese da acne diminuindo a proliferação, diferenciação e atividade dos sebócitos basais, induzindo apoptose dessas células, normalizando a queratinização folicular e inibindo a comedogênese. ${ }^{10}$ É utilizada para 0 tratamento das formas graves da acne como a nodulocística e acne moderada resistente ao tratamento convencional. $7,10,11,14,15$ É contra indicada em mulheres grávidas, insuficiência hepática, hipervitaminose A, hiperlipidemias e deve ser utilizada com precaução em pacientes com antecedentes depressivos.,10,11,19 Os principais efeitos adversos são eritema, ressecamento da pele, dermatites faciais, ${ }^{19,21,26}$ alterações de humor, aumento dos níveis sanguíneos de colesterol total e triglicerídeos, e teratogenicidade, o que implica a necessidade do impedimento da gravidez ${ }^{8,10,11,19,26}$ durante a utilização e, por no mínimo, 6 meses após 0 término do tratamento, ${ }^{8,19,26}$ sendo, também, contra indicada na amamentação. ${ }^{19,20}$ Casos de depressão, psicoses, pensamentos e atentados suicidas em pacientes que utilizam este medicamento, também foram relatados. ${ }^{7,8,10,19}$ No entanto, não existe relação causal entre isotretinoína e depressão, 10,11,19,26,28 não estando, ainda, estabelecido a causa ou mecanismo que produza este tipo de manifestação. ${ }^{14,15,17,29}$ Portanto, na ausência de comprovação científica definitiva, aconselha-se aos médicos ter cautela e acompanhar os pacientes quanto ao reconhecimento precoce de sintomas psiquiátricos. ${ }^{10}$ Interações da isotreinóina ocorre com a fenitoína, por aumentar o risco de perda óssea, com tetraciclinas por risco de hipertensão intracraniana, com vitamina A por riscos tóxicos aditivos, com microdoses de progesterona, etinilestradiol, por redução de seus níveis sanguíneos (aconselha-se métodos contraceptivos adicionais), com erva de São João, por diminuir o efeito dos contraceptivos orais. ${ }^{10} \mathrm{~A}$ absorção de isotretinoína é aumentada com alimentos, ${ }^{10,25}$ devendo, portanto, ser administrada junto às refeições. ${ }^{20}$ Recomenda-se iniciar 0 tratamento com doses de $0,5 \mathrm{mg} / \mathrm{Kg} / \mathrm{dia}$ a 1 $\mathrm{mg} / \mathrm{Kg} / \mathrm{dia} \cdot{ }^{10,11,15,20} \mathrm{~A}$ dose de manutenção deve ser ajustada a cada paciente, situando-se entre $0,1 \mathrm{mg} / \mathrm{kg} / \mathrm{dia}$ a $1 \mathrm{mg} / \mathrm{kg} / \mathrm{dia} .{ }^{15,20}$ Durante 0 tratamento com isotretinoína, 0 monitoramento clínico laboratorial é essencial através de testes de glicose, creatina quinase, triglicerídeos, colesterol, funções hepáticas, gravidez e possíveis efeitos oculares e psicológicos. ${ }^{10}$

Saúde (Santa Maria), v.36, n.2, p. 39-54,

jul./dez. 2010.

Atenção farmacêutica em dermatologia: fármacos antiacneicos

Os agentes abrasivos como enxofre e ácido salicílico, provocam descamação, esfoliação e, consequentemente, irritação. Nem todos os irritantes tópicos diminuem os comedões ou impedem a formação de lesões. Agem como um trauma adicional à pele já inflamada. ${ }^{14,15}$ 
O ácido salicílico possui efeito queratolítico, ${ }^{12,14,19}$ sendo contra indicado em pacientes com insuficiência circulatória, ${ }^{19,20} \mathrm{em}$ verrugas, marcas de nascença ou papilas nas quais haja pêlos. ${ }^{20}$ Encontra-se disponível comercialmente em concentrações de $0,5 \%$ a $2 \%$ em cremes e loções. Aplica-se na pele afetada duas ou três vezes ao dia. ${ }^{15,20}$

O enxofre é utilizado na forma de sabonete ou cremes de limpeza ${ }^{15,22,31}$ na concentração de $2 \%{ }^{31}$ É contra indicado em pacientes com hipersensibilidade ao enxofre. Não aplicar juntamente com retinóides e antibióticos. ${ }^{20}$ Recomenda-se aplicar duas vezes ao dia na pele afetada. $^{20}$

Os contraceptivos orais são efetivos em mulheres com acne severa, desordens hormonais e em pacientes com tratamento refratário e prolongado com antibióticos. ${ }^{7,12,15}$ Estes medicamentos inibem a ovulação através do bloqueio de receptores androgênicos, também inibem a produção de sebo, diminuindo, assim, o substrato para as bactérias e os níveis de ácido graxos. ${ }^{12,15} \mathrm{~A}$ associação mais comum é etinilestradiol $(0,3 \mu \mathrm{g}) /$ /acetato de ciproterona (2 mg), sendo recomendada uma dose diária, preferencialmente no mesmo horário. ${ }^{19,20}$ É contra indicado em pacientes com risco cardiovascular, antecedentes tromboembólicos, câncer (exceto de próstata), ${ }^{11,19}$ hepatopatias,19 gravidez, lactação e amenorréia. ${ }^{20}$ Os efeitos adversos mais frequentes são transtornos gastrointestinais, cefaléia e retenção de água. ${ }^{12,15,19}$ Os mais graves são embolia pulmonar, veias varicosas, ginecomastia, problemas hepáticos, $7,20,25$ hipertensão e aumento de risco cardiovascular. ${ }^{11,19}$ Está ainda relacionado, a maior incidência de câncer de colo uterino e de mama. ${ }^{19}$ Os antibacterianos rifabutina e rifampicina; os anticonvulsivantes barbitúricos, carbamazepina, fenitoína e topiramato; 0 antimicótico griseofulvina; os antivirais nelfinavir, ritonavir e nevirapina são indutores enzimáticos do citocromo P-450 aumentando o metabolismo do anticoncepcional diminuindo, assim, 0 seu efeito. ${ }^{25}$

As informações de maior relevância para o paciente e para o farmacêutico de cada medicamento estão organizadas na forma de "Mini bulas" e tabela (tabela-1) apresentadas a seguir: 


SUBSTÂNCIA QUÍMICA: Tetraciclina
Nomes comerciais:
(Parenzyme Tetraciclina®, Tetrex®,
Tetramicin®).
Posologia:
Cápsulas 500 mg, 2 vezes ao dia com água.
Efeitos adversos:
Transtornos gastrointestinais e renais,
hepatotoxidade, $\quad$ fotossensibilidade
candidíase vaginal.
Interações medicamentosas e alimentares:
Retinóides, pectina, antiácidos, metoxiflurano,
alimentos que contenham cálcio, magnésio e
ferro.
Contra indicações:
Insuficiência hepática e renal, gravidez e em
crianças.

\section{SUBSTÂNCIA QUIIMICA: Clindamicina}

Nomes comerciais:

(Clinagel $囚$, Dalacin $\mathrm{\top} 囚$ ).

\section{Posologia:}

Gel $3 \%$ ou solução $10 \mathrm{mg} / \mathrm{ml}$, aplicar 2 vezes ao dia na pele afetada.

\section{Efeitos adversos:}

Dermatites de contato, enrijecimento, irritação e descamação da pele.

Interações medicamentosas:

Antibióticos e cetoconazol.

\section{Contra indicações:}

$\mathrm{Na}$ hipersensibilidade à lincomicina, doenças renais e hepáticas, e antecedentes de colites.

\section{SUBSTÂNCIA QUÍMICA: Eritromicina}

Nomes comerciais:

Uso oral: (llosone®, Eritrex $₫)$.

Uso tópico: (llosone tópicoß).

Posologia:

Comprimidos $250 \mathrm{mg}$ ou $500 \mathrm{mg}, 2$ comprimidos a cada 12 horas ou 1 comprimido a cada 6 horas com água.

Creme (1,5\% a $4 \%$ ), aplicar 2 vezes ao dia.

Efeitos adversos:

Náuseas e perda de audição. Descamação, ressecamento e irritação principalmente por via tópica.

Interações medicamentosas:

Carbamazepina, digoxina, ciclosporina, varfarina, isotretinoína e clindamicina.

\section{Contra indicações:}

Gravidez, amamentação e

hepatopatias.

\section{SUBSTÂNCIA QUÍMICA: Peróxido de Benzoíla}

Nomes comerciais:

(Benzac $囚$, Panoxyl@ $\circledast$ ).

\section{Posologia:}

Gel ou creme ( $1 \%$ a $10 \%)$, aplicar 2 vezes ao dia na pele afetada.

Efeitos adversos:

Ressecamento, sensação de ardor e enrijecimento da pele.

Interações medicamentosas:

Antibióticos e retinóides.

\section{Contra indicação:}

$\mathrm{Na}$ hipersensibilidade ao peróxido de benzoíla e sobre a pele irritada ou queimada pelo vento ou pelo sol. 


\section{SUBSTÂNCIA QUIIMICA: \\ Ácido azelaico \\ Nome comercial: \\ (Azelam®). \\ Posologia:}

Creme ou gel ( $5 \%$ a $15 \%$ ), aplicar 2 vezes ao dia na pele afetada.

\section{Efeitos adversos:}

Irritação local e fotossensibilização.

Interação medicamentosa:

Não há referência.

Contra indicação:

Não há referência.

\section{SUBSTÂNCIA QUÍMICA: Isotretinoína}

\section{Nome comercial:}

(Roacutan囚).

\section{Posologia:}

Cápsulas de $10 \mathrm{mg}$ ou $20 \mathrm{mg}, 1$ ou 2 vezes ao dia durante as refeições.

\section{Efeitos adversos:}

Eritema, ressecamento da pele, alterações de humor, fotossensibilidade, teratogenicidade, aumento do colesterol total e triglicerídeos.

\section{Interações medicamentosas:}

Fenitoína, tetraciclinas, vitamina $\mathrm{A}$, com doses baixas (microdoses) de progesterona, etinilestradiol e com erva de São João.

\section{Contra indicações:}

Gravidez, hiperlipidemias e hipervitaminose A. Utilizar com precaução em pacientes com antecedentes depressivos.

\section{SUBSTÂNCIA QUÍMICA: Tretinoína}

\section{Nomes comerciais:}

(Vitacid $囚$, Locacid $囚$, Retin- $A \circledast$ ).

Posologia:

Creme $0,1 \%$ ou gel $0,1 \%$, aplicar 1 a 2 vezes ao dia na pele afetada.

\section{Efeitos adversos:}

Irritação da pele, eritema e fotossensibilidade.

Interações medicamentosas:

Medicamentos tópicos de alta concentração alcoólica, tetraciclinas e vitamina $A$.

Contra indicações:

Gravidez, hiperlipidemias, insuficiência hepática e hipervitaminose $\mathrm{A}$.

\section{SUBSTÂNCIA QUÍMICA: Tazaroteno}

Nome comercial:

(Zorac®).

\section{Posologia:}

Creme $0,1 \%$ ou gel $0,1 \%$, aplicar 1 vez ao dia na pele afetada, preferencialmente à noite.

\section{Efeitos adversos:}

Irritação, descamação, ressecamento da pele e fotossensiblidade.

Interações medicamentosas:

Vitamina A.

Contra indicações:

Pele eczematosa e gravidez.
Saúde (Santa Maria), v.36, n.2, p. 39-54, jul./dez. 2010

Piana,M.; Canto, G. S.

ISSN 2236-5843 


\section{SUBSTÂNCIA QUIIMICA: \\ Adapaleno}

Nome comercial:

(Differin®).

\section{Posologia:}

Gel $0,1 \%$ ou solução $0,1 \%$, aplicar 1 vez ao dia na pele afetada, preferencialmente à noite.

Efeitos adversos:

Eritema, prurido, descamação da pele e fotossensibilidade.

Interações medicamentosas:

Medicamentos tópicos de ação similar não devem ser usados concomitantemente.

Contra indicação:

Gravidez.

\section{SUBSTÂNCIA QUIIMICA:}

Enxofre

\section{Nome comercial:}

(Acnase®) enxofre $2 \%$ / peróxido de benzoila $5 \%$.

Posologia:

Sabonete ou creme de limpeza, utilizar 2 vezes ao dia.

Efeitos adversos:

Irritação.

Interações medicamentosas:

Retinóides e antibióticos.

Contra indicações:

Na hipersensibilidade ao enxofre.

\section{SUBSTÂNCIA QUIIMICA:}

Ácido salicílico

\section{Nomes comerciais:}

(Salder $\mathrm{S} \circledast$ ) acido salicílicos $3 \%$ / enxofre 10 $\%$, (Sastid®) acido salicílico $3 \%$ / enxofre 10 $\%$.

\section{Posologia:}

Creme ou loção $(0,5 \%$ a $2 \%)$, aplicar na pele afetada 2 ou 3 vezes ao dia.

\section{Efeitos adversos:}

Esfoliação, descamação e irritação. Interação medicamentosa:

Não há referência.

Contra indicações:

Insuficiência circulatória, em verrugas ou papilas com pêlos.

\section{SUBSTÂNCIA QUÍMICA: Etinilestradiol e} Acetato de ciproterona

Nomes comerciais:

(Diane ${ }^{\circledR}$, Selene®).

\section{Posologia:}

Tomar 1 comprimido de etinilestradiol $(0,35$ $\mu \mathrm{g}) /$ acetato de ciproterona $(2 \mathrm{mg})$ por dia, preferencialmente no mesmo horário.

\section{Efeitos adversos:}

Embolia pulmonar, veias varicosas e hepatopatias.

Interações medicamentosas:

Rifabutina, rifampicina, barbitúricos, carbamazepina, fenitoína, griseofulvina, nelfinavir, ritonavir e nevirapina diminuem 0 seu efeito.

\section{Contra indicações:}

Risco cardiovascular, antecedente de transtornos tromboembólicos, câncer, hepatopatias, gravidez e amamentação. 
Tabela 1 - Principais Fármacos prescritos na terapia antiacneica

\begin{tabular}{|c|c|c|c|c|c|c|c|}
\hline PRINCÍPIO ATIVO & NOMES COMERCIAIS & EFEITOS ADVERSOS & POSOLOGIA & INTERAÇÕES & CONTRA INDICAÇÕES & RISCO NA GRAVIDEZ & \\
\hline $\begin{array}{l}\text { Ácido } \\
\text { azelaico }\end{array}$ & Azelan® & $\begin{array}{l}\text { Hipopigmentação; } \\
\text { Irritação; } \\
\text { Fotossensibilização }\end{array}$ & $\begin{array}{l}\text { Creme ou gel de } 5 \% \text { a } \\
10 \% \text {, aplicar de } 2 \text { vezes } \\
\text { ao dia. }\end{array}$ & $\begin{array}{l}\text { Uso com peróxido de } \\
\text { benzoíla, clindamicina e } \\
\text { tretinoína aumentam a } \\
\text { eficácia. }\end{array}$ & - & $\begin{array}{c}\text { Não há estudos } \\
\text { adequados, é excretado } \\
\text { no leite. }\end{array}$ & \\
\hline Ácido salicílico & $\begin{array}{c}\text { Sastid® (acido salicílico } \\
3 \%+\text { enxofre 10\%) } \\
\text { Salder S } ® \text { (acido } \\
\text { salicílico } 3 \%+\text { enxofre } \\
10 \%\end{array}$ & $\begin{array}{c}\text { Irritação; } \\
\text { Descamação }\end{array}$ & $\begin{array}{c}\text { Creme ou loção de } 0,5 \% \\
\text { a } 2 \% \text {, aplicar de } 2 \text { a } 3 \\
\text { vezes ao dia. }\end{array}$ & - & $\begin{array}{l}\text { Insuficiência circulatória; } \\
\qquad \text { Verrugas; } \\
\text { Marcas de nascença ou } \\
\text { papilas com pêlos }\end{array}$ & $\begin{array}{l}\text { Não há estudos } \\
\text { adequados. }\end{array}$ & \\
\hline Adapaleno & Differin® & $\begin{array}{c}\text { Eritema; } \\
\text { Prurido; } \\
\text { Descamação }\end{array}$ & $\begin{array}{l}\text { Gel ou solução a 0,1%, } \\
\text { aplicar } 1 \text { vez ao dia. }\end{array}$ & $\begin{array}{c}\text { Retinóides ou } \\
\text { medicamentos tópicos de } \\
\text { ação similar não devem } \\
\text { ser usados } \\
\text { concomitantemente. }\end{array}$ & $\begin{array}{l}\text { Hipersensibilidade ao } \\
\text { adapaleno. }\end{array}$ & $\begin{array}{c}\text { Contra indicada na } \\
\text { gravidez devido ao efeito } \\
\text { teratogênico. }\end{array}$ & \\
\hline Clindamicina (tópica) & $\begin{array}{l}\text { Clinage } 1 \circledR \\
\text { Dalacin } T \circledast\end{array}$ & $\begin{array}{c}\text { Enrijecimento; } \\
\text { Descamação; } \\
\text { Irritação local; Dermatite de } \\
\text { contato }\end{array}$ & $\begin{array}{l}\text { Gel a } 3 \% \text { ou solução } \\
\text { tópica } 10 \mathrm{mg} / \mathrm{ml} \text {, aplicar } 2 \\
\text { vezes ao dia. }\end{array}$ & $\begin{array}{c}\text { Ação diminuída quando } \\
\text { associado ao cetoconazol } \\
\text { e } \\
\text { Antibióticos. }\end{array}$ & $\begin{array}{c}\text { Doenças renais e } \\
\text { hepáticas; } \\
\text { Hipersensibilidade à } \\
\text { lincomicina; Antecedentes } \\
\text { de colite }\end{array}$ & $\begin{array}{l}\text { Não há estudos } \\
\text { adequados. }\end{array}$ & \\
\hline Enxofre & $\begin{array}{l}\text { Acnase } \AA \text { (peróxido de } \\
\text { benzoila/enxofre) }\end{array}$ & Irritação & $\begin{array}{l}\text { Creme ou sabonete a } 2 \\
\%, \text { aplicar } 2 \text { vezes ao dia. }\end{array}$ & $\begin{array}{l}\text { Retinóides; } \\
\text { Antibióticos }\end{array}$ & $\begin{array}{l}\text { Hipersensibilidade ao } \\
\text { enxofre. }\end{array}$ & $\begin{array}{l}\text { Não há estudos } \\
\text { adequados. }\end{array}$ & \\
\hline $\begin{array}{l}\text { Eritromicina } \\
\text { (oral) }\end{array}$ & $\begin{array}{l}\text { Eritrex® } \\
\text { llosone® }\end{array}$ & $\begin{array}{c}\text { Distúrbios gastrointestinais; } \\
\text { Perda de audição }\end{array}$ & $\begin{array}{c}\text { Comprimidos de } 250 \mathrm{mg} \\
\text { ou } 500 \mathrm{mg}, 2 \text { comprimidos } \\
2 \text { vezes ao dia ou } 1 \\
\text { comprimido a cada } 6 \\
\text { horas. }\end{array}$ & $\begin{array}{c}\text { Varfarina; } \\
\text { Carbamazepina; } \\
\text { Digoxina; } \\
\text { Ciclosporina; }\end{array}$ & $\begin{array}{l}\text { Hepatopatias; } \\
\text { Hipersensibilidade à } \\
\text { eritromicina }\end{array}$ & $\begin{array}{c}\text { Contra indicada na } \\
\text { gravidez e na amamentação } \\
\text { pois atravessa a placenta e } \\
\text { distribui-se no leite materno. }\end{array}$ & $\begin{array}{l}\text { Saúde (Santa Maria), v.36, n.2., p.39-54, } \\
\text { jul/ddez. 2010 } \\
\text { Piana,M.; Canto, G. S. } \\
\text { ISSN 2236-5843 }\end{array}$ \\
\hline
\end{tabular}




\begin{tabular}{|c|c|c|c|c|c|c|}
\hline Eritromicina (tópica) & $\begin{array}{l}\text { llosone® } \\
\text { tópico }\end{array}$ & $\begin{array}{l}\text { Ressecamento; Irritação; } \\
\text { Descamação }\end{array}$ & $\begin{array}{l}\text { Creme de } 1,5 \% \text { a } 4 \% \text {, } \\
\text { aplicar } 2 \text { vezes ao dia. }\end{array}$ & $\begin{array}{c}\text { Isotretinoína, } \\
\text { Clindamicina; Substâncias } \\
\text { tópicas irritantes }\end{array}$ & 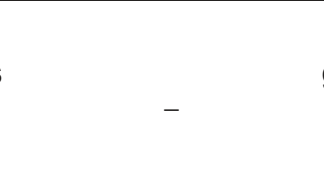 & $\begin{array}{l}\text { Contra indicada na } \\
\text { gravidez e na amamentação } \\
\text { pois atravessa a placenta e } \\
\text { distribui-se no leite materno. }\end{array}$ \\
\hline $\begin{array}{l}\text { Etinilestradiol/ acetato } \\
\text { de ciproterona }\end{array}$ & $\begin{array}{l}\text { Diane® } \\
\text { Selene® }\end{array}$ & $\begin{array}{l}\text { Embolia pulmonar; } \\
\text { Veias varicosas; } \\
\text { Ginecomastia; } \\
\text { Problemas hepáticos; } \\
\text { Hipertensão }\end{array}$ & $\begin{array}{l}\text { Etinilestradiol (0,035 mg) } \\
\text { lacetato de ciproterona ( } \\
\qquad 2 \mathrm{mg}) \text {, } \\
\text { administrar } 1 \text { vez ao dia. }\end{array}$ & $\begin{array}{c}\text { Rifampicina; } \\
\text { Rifabutina; } \\
\text { Barbitúricos; } \\
\text { Carbamazepina; } \\
\text { Fenitoína; } \\
\text { Griseofulvina; } \\
\text { Nelfinavir; } \\
\text { Ritonavir; } \\
\text { Nevirapina; }\end{array}$ & $\begin{array}{l}\text { Câncer (exceção de } \\
\text { próstata); } \\
\text { Lactação; } \\
\text { Hepatopatias; } \\
\text { Risco cardiovascular; } \\
\text { Antecedentes } \\
\text { tromboembólicos; } \\
\text { Amenorréia; }\end{array}$ & $\begin{array}{l}\text { Anormalidade em fetos, é } \\
\text { excretado no leite. }\end{array}$ \\
\hline Isotretinoína & Roacutan® & $\begin{array}{l}\text { Eritema; Ressecamento da } \\
\text { pele, mucosa e olhos; } \\
\text { Dermatites faciais; Alteração } \\
\text { de humor; Eczema; } \\
\text { Fotossensibilidade; } \\
\text { Aumentos dos níveis de } \\
\text { colesterol total e } \\
\text { triglicerídeos }\end{array}$ & $\begin{array}{c}\text { 0,5 mg/Kg/dia a } 1 \\
\mathrm{mg} / \mathrm{Kg} / \mathrm{dia} \text { por } 6 \text { a } 12 \\
\text { semanas. }\end{array}$ & $\begin{array}{l}\text { Fenitoína; } \\
\text { Tetraciclinas; } \\
\text { Vitamina A; } \\
\text { Progesterona } \\
\text { (microdoses); } \\
\text { Etinilestradiol; } \\
\text { Erva de São João; }\end{array}$ & $\begin{array}{c}\text { Insuficiência hepática; } \\
\text { Hipervitaminose A; } \\
\text { Valores de lipídeos } \\
\text { sanguíneos elevados; } \\
\text { Utilizar com precaução } \\
\text { em pacientes depressivos; } \\
\text { Amamentação }\end{array}$ & $\begin{array}{l}\text { Contra indicada na } \\
\text { gravidez devido ao efeito } \\
\text { teratogênico. }\end{array}$ \\
\hline Peróxido de Benzoíla & $\begin{array}{l}\text { Benzac® } \\
\text { Panoxyl® }\end{array}$ & $\begin{array}{l}\text { Ressecamento; } \\
\text { Sensação de ardor; } \\
\text { Enrijecimento }\end{array}$ & $\begin{array}{l}\text { Gel ou creme de } 1 \% \text { a } \\
10 \%, \\
\text { aplicar } 1 \text { a } 2 \text { vezes ao } \\
\text { dia. }\end{array}$ & Retinóides tópicos & $\begin{array}{l}\text { Hipersensibilidade ao } \\
\text { peróxido de Benzoíla; } \\
\text { Sobre a pele irritada ou } \\
\text { em queimaduras pelo } \\
\text { vento ou pelo sol. }\end{array}$ & $\begin{array}{l}\text { Não há estudos } \\
\text { adequados. }\end{array}$ \\
\hline
\end{tabular}




\begin{tabular}{|c|c|c|c|c|c|c|}
\hline Tazaroteno & Zorac $®$ & $\begin{array}{c}\text { Irritação; } \\
\text { Descamação; } \\
\text { Ressecamento; } \\
\text { Sensação de queimação }\end{array}$ & $\begin{array}{c}\text { Creme ou gel de } 0,05 \% \\
\text { a } 0,1 \% \text {, aplicar } 1 \text { vez ao } \\
\text { dia }\end{array}$ & Vitamina A & Em pele eczematosa. & $\begin{array}{c}\text { Contra indicada na } \\
\text { gravidez devido ao efeito } \\
\text { teratogênico. }\end{array}$ \\
\hline Tetraciclina & $\begin{array}{c}\text { Parenzyme® } \\
\text { Tetraciclina® } \\
\text { Tetrex® } \\
\text { Tetramicin } \circledast\end{array}$ & $\begin{array}{c}\text { Fotossensibilidade; } \\
\text { Indução à hepatotoxidade; } \\
\text { Pancreatites; } \\
\text { Toxicidade do sistema } \\
\text { nervoso central; } \\
\text { Enterocolite; } \\
\text { Vaginite por Cândida; } \\
\text { Tronstornos renais }\end{array}$ & $\begin{array}{l}\text { Cápsulas de } 500 \text { mg, } \\
\text { administrar } 2 \text { vezes ao } \\
\text { dia. }\end{array}$ & $\begin{array}{l}\text { Leite e alimentos que } \\
\text { contenham cálcio, } \\
\text { magnésio, e ferro; } \\
\text { Antiácidos; } \\
\text { Metoxiflurano; } \\
\text { Retinóides; } \\
\text { Pectina e colestipol }\end{array}$ & $\begin{array}{l}\text { Insuficiência renal e } \\
\text { hepática; } \\
\text { Crianças menores de } 9 \\
\text { anos }\end{array}$ & $\begin{array}{l}\text { Contra indicada devido a } \\
\text { problemas na dentição das } \\
\text { crianças (manchas). }\end{array}$ \\
\hline Tretinoína & $\begin{array}{l}\text { Vitacid® } \\
\text { Locacid® } \\
\text { Retin-A® }\end{array}$ & $\begin{array}{l}\text { Ardor; } \\
\text { Irritação; } \\
\text { Eritema }\end{array}$ & $\begin{array}{c}\text { Creme } 0,1 \% \text { ou gel a } 0,1 \\
\% \text {, aplicar } 1 \text { a } 2 \text { vezes ao } \\
\text { dia. }\end{array}$ & $\begin{array}{l}\text { Medicamentos tópicos de } \\
\text { alta concentração } \\
\text { alcoólica. }\end{array}$ & $\begin{array}{c}\text { Diabetes mellitus; } \\
\text { Hiperlipidemias; } \\
\text { Hipervitaminose A; } \\
\text { Insuficência hepática }\end{array}$ & $\begin{array}{l}\text { Contra indicada na } \\
\text { gravidez devido ao efeito } \\
\text { teratogênico. }\end{array}$ \\
\hline
\end{tabular}




\section{Conclusão}

A acne por ser uma doença cada vez mais freqüente, levando a população, principalmente, jovem a transtornos emocionais, a cura está relacionada não somente ao tratamento, mas também ao nível de estresse gerado nos pacientes. Neste sentido, por existir uma ampla variedade de medicamentos empregados no tratamento da acne, alguns com potencial toxicidade, o relacionamento entre farmacêutico e paciente torna-se imprescindível para uma farmacoterapia bem sucedida. Deste modo, a informação clara sobre a melhor forma de realizar o tratamento, utilizando os medicamentos de forma correta e esclarecendo as possíveis reações adversas e interações medicamentosas, contribuirão de forma efetiva, para minimizar os riscos da automedicação, das intoxicações medicamentosas e do abandono do tratamento. a atenção farmacêutica promoverá, portanto, um atendimento personalizado, humanizado e cientificamente correto.

\section{Referências Bibliográficas}

1. Reis AM. Atenção farmacêutica e promoção do uso racional de medicamentos. Revista espaço para Saúde 2002. [periódico na Internet]. 2010 dez. Disponível em hppp://www./ccs.uel.br/espacoparasaude/v4n2/doc/atençãofarmauso.doc.

2. Mikalauscas MMV, Gonzales RMB. A formação humanística do farmacêutico. Infarma 2004; 16(3/4): 67-69.

3. Silva DD, Prando LE. As dificuldades do profissional farmacêutico para implantação da atenção farmacêutica e da farmacovigilância nas farmácias hospitalares e comunitárias. Infarma 2004; 16(11/12): 85-88.

4. Santos JS. Ensino farmacêutico: por que é preciso mudar? Pharmacia Brasileira 2008; 64: 4-5.

5. Rolim RA. Atenção farmacêutica: um processo educativo. Infarma 2008; 20(3/4): 23-25.

6. Machado PEB, Matos VC, Romeu GA. Importância da atenção farmacêutica para o paciente hipertenso. Infarma 2008; 20(3/4): 10-15.

7. Thiboutot D. New treatments and therapeutic strategies for acne. Arch Fam Med 2000; 9(2): 179-187.

8. Webster GF. Clinical review: Acne vulgaris. British medical journal 2002; 325: 475-479.

9. Meneses C, Bouzas I. Acne vulgar e adolescência. Adolescência \& Saúde 2009; 6(3).

10. Rigopoulos D, George L, Katsambas DA. The role of isotretinoin in acne therapy: why not as first-line therapy? facts and controversies. Clinics in Dermatology 2010; 28(1): 24-30.

11.Nguyen R, Su J. Treatment of acne vulgaris. Paediatrics and Child Health 2011; 21(3): 119-125.

12. Herane Ml. Actualización terapéutica en acne vulgaris. Dermatol Pediatr Lat 2005; 3(1): 5-19.

13. Ramos-e-silva M, Carneiro SCS, Ponzio HA, Assunção BFG, Cardoso AE, Almeida FA et al. Estudo clínico aberto multicêntrico da efetividade e tolerabilidade do gel de adapaleno a 0,1\% em pacientes com acne vulgar. An bras dermatol 2003; 78(2): 155-168.

14. Guzzo CA, Lazarus G, Weth VP. Dermatologia. In: Goodman \& Gilman As bases farmacológicas da terapêutica. 9nd ed. Rio de Janeiro(RJ): McGraw-Hill Interamericana Editores, 1996. p. 1184-1195

Saúde (Santa Maria), v.36, n.2, p. 39-54,

jul./dez. 2010.

Atenção farmacêutica em dermatologia:

fármacos antiacneicos

ISSN 2236-5834
15. Herra CG. El acne y su tratamiento. Centro nacional de información de medicamentos. Universidad de Costa Rica. Costa Rica 2003. [periódico na Internet]. 2010 dez. Disponível em http://www.sibdi.bldt.ucr.ac.cr/CIMED/Cimed0.pdf.

16. Ministério da Saúde. Protocolo clínico de diretrizes terapêuticas 2010. 
17. Wannmache L. Antimicrobianos em dermatologia. Uso racional de medicamentos 2006; 3(12): 1-5.

18. Romiti R, Jansen T, Plewig G. Acne fulminans. An bras dermatol 2000; 75(5): 611-617.

19. Martindale. Guía completa de consulta fármaco-terapéutica. 2nd ed. Barcelona: Pharma Editores; 2006.

20. Favano A, Godoy FZ, Zanette K, Caetano. BPR Guia de Remédios®. 8nd ed. São Paulo(SP): Editora Escala; 2007.

21. Remington. Farmacia. 17nd ed. Argentina: Médica Panamericana; 1992.

22. Korolkovas A, Franca FFAC, Cunha BCA. Dicionário terapêutico Guanabara. 2005/2006 ed. Rio de Janeiro(RJ): Guanabara Koogan; 2005.

23. Corrêa CC, Corrêa VLF. Antibióticos no dia-a-dia. 2nd ed. Rio de Janeiro(RJ): Rubio; 2001.

24. Cordás TA, Barreto OCO. Interações medicamentosas. São Paulo(SP): Editorial Lemos; 1998.

25. Stockley. Interacciones farmacológica. 2nd ed. Barcelona: Pharma Editores; 2006.

26. Haider A, Schaw JC. Treatment of acne vulgaris. JAMA 2004; 202(6): 726-735.

28. $\mathrm{Ng} \mathrm{CH}$, Tam MM, Celi E, Tate B, Schweitzer I. Prospective study of depressive symptoms and quality of life in acne vulgaris patients treated with isotretinoin compared to antibiotic and topical therapy. Australas $\mathrm{J}$ Dermatol 2002; 43(4): 262-268.

29. Magin P, Pond D, Smith W. Isotretinoin, depression and suicide: a review of the evidence. British Journal of General Practice 2005; 55(511): 134-138.

30. Shalita A, Berson D, Thiboutot D, Leyden J, Parizadeh D, Sefton J et al. Effects of tazarotene $0,1 \%$ cream in the treatment of facial acne vulgaris: Pooled results from two hulticenter, double-blind, randomized, vehiclecontrolled, parallel-group trials. Clin Ther 2004; 26(11): 1865-1873.

31. Serra-baldrich E, Lin AN, Reimer RJ, Carter DM. Azufre, compuestos y usos. Journal of the Ameritan Academy of Dermatology 1988; 18: 163-170.

Mariana Piana - Dr. Pantaleão, 150, apto 101. CEP 97010-180. Santa Maria. Fone: 91481854 (55)

E-mail -marianarpiana@gmail.com

Recebido em 21 de janeiro de 2011.

Aprovado em 16 de junho de 2011.

Saúde (Santa Maria), v.36, n.2, p. 39-54, 